\title{
Freedom of Information Acts in the Developing World: Lessons from the Caribbean for the Bahamian Experience
}

\author{
Lisa Benjamin \\ University of The Bahamas ${ }^{1}$
}

\section{Abstract}

Freedom of Information Acts (FOIAs) can provide countries with a platform to enshrine transparency, deepen democracy and combat corruption. A number of FOIAs or Right to Information Acts have been passed in the last 20 years, particularly in developing countries and including in the Caribbean region. These initiatives have encountered similar problems, including lack of implementation and enforcement, potentially due to weak institutional systems. The lack of implementation may also be due to contradictory domestic incentives; FOIAs are designed to induce transparency and the provision of information, but also impose constraints and administrative burdens on governments. This article looks at the international context of FOIAs and analyses some of the recent problems of implementation, particularly in developing countries and specifically in the Caribbean region. The article then takes a detailed look at the amendment process and passage of the FOIA 2017 Act in The Bahamas, which is illustrative of these conflicting incentives.

\section{Introduction}

Freedom of Information Acts (FOIAs) can provide countries with a platform to enshrine transparency, deepen democracy and combat corruption. Transparency and anti-corruption initiatives have spread rapidly around the world in the past 20 years (Schnell, 2015, p. 277). These initiatives have been spearheaded by the passage of a FOIA or Right to Information Act, which can prove to be a "foundational factor" (Trapnell \& Lemieux, 2014, p. 7) in the institutionalization of transparency and good governance. As a result, a number of FOIAs have been passed in the last 20 years, particularly in developing countries and including in the Caribbean region. A number of common experiences have been encountered, particularly by developing countries, in relation to FOIAs. Problems with implementation and institutional capacity constraints have been particularly rife (LaMay, Freeman, \& Winfield, 2013, p. 20).

Issues with implementation may be in part due to the adoption of model FOIAs more appropriate to developed countries, but also

\footnotetext{
${ }^{1}$ Lisa Benjamin, LL.B. Programme, Social Sciences, University of The Bahamas

Email: lisa.benjamin@ub.edu.bs

Acknowledgments: I was a member of the Freedom of Information Act Working Committee from November 2015 to January 2017 representing civil society. My views do not necessarily represent those of the Committee.
}

APA reference: Benjamin, L. (2017). Freedom of information acts in the developing world: Lessons from the Caribbean for the Bahamian experience. International Journal of Bahamian Studies, 23, 7-14. https://doi.org/10.15362/ijbs.v23i0.292

(C) L. Benjamin, 2017. Journal compilation (c) International Journal of Bahamian Studies, 2017 
due to contradictory domestic incentives; FOIAs are designed to induce transparency and the provision of information, but also impose constraints and administrative burdens on governments (Schnell, 2015, p. 277). The passage and implementation of a FOIA may involve paradoxical incentives on behalf of governments, leading to benign or purposeful neglect in the implementation of these regimes.

This paper looks at the international context of FOIAs and analyses some of the recent problems of implementation, particularly in developing countries and in the Caribbean region. It then takes a detailed look at the process of amending and passing the 2017 Act in The Bahamas, which is illustrative of these conflicting domestic incentives. Several town halls were held throughout The Bahamas to elicit public comment. I attended three town hall meetings, held on April 18, 2016, May 10, 2016 and June 20, 2016, and noted firsthand the public comment offered. This commentary is useful here in depicting local resistance to the Bill. I also attended the Parliamentary debate on the Bill on January 31, 2017 and made contemporaneous notes on the discussion.

The article concludes with some lessons that can be learned from other developing countries and in particular the Caribbean, lessons that could smooth the implementation process of FOIA in The Bahamas.

\section{FOIAs and Developing Countries: implementation and capacity constraints}

The growth in the passage of FOIAs around the globe in the past 20 years has been impressive. This growth is partly due to the desire to enshrine transparency, deepen democracy and combat corruption. As LaMay et al. (2013) state, "Access to information is to citizenship in the information age what civil, political and social rights were to the industrial age" (p. 11). Increased transparency can lead to political and economic benefits for countries, including fewer conflicts with neighbouring countries, more efficient markets, greater technological innovation, and a more reliable investment climate (LaMay et al., 2013, p. 13). Access to information can create a "virtuous cycle" by creating open societies that are better placed to create and share data, which consequentially drives development-related improvements in areas such as food security, agriculture, health infrastructure and innovation (IFLA \& Technology and Social Change Group, 2017, p. 8). In the context of the developing world, the passage of a FOIA can often be due to pressure from domestic or international civil society groups, as well as from other institutional organizations such as the World Bank (Schnell, 2015, p. 277; Roberts, 2010, p. 925; Shepherd, 2015, p. 716). In developing countries in particular, the passage of a FOIA can also be part of deeper public-service reform efforts required by international funding agencies (Shepherd, 2015, p. 716). However, developing countries that have recently adopted FOIAs are generally less affluent than developed countries, have weaker institutional and legal systems, and suffer from capacity constraints (Roberts, 2015, p. 925). Schnell (2015) has argued that these factors have resulted in an "insincere mimicry" of FOIA regimes within developing countries as the result of two competing pressures: the desire for external legitimacy, countered by domestic resistance to FOIAs ( $\mathrm{p}$. 277).

FOIAs are peculiar in that they can lead to democratic public goods as outlined above, but they do so by imposing financial and administrative constraints on governments, and particularly decision-makers (Schnell, 2015 , p. 277). This phenomenon can lead to some of the implementation problems seen in developing countries (Roberts, 2010, p. 926). 
Delays or lack of responses to FOIA requests are common complaints across the globe, particularly in developing countries (LaMay et al., 2013, p. 17). LaMay et al. (2013) found that around the world, on average, fewer than $50 \%$ of FOIA requests were fulfilled, and approximately $36 \%$ were simply unanswered, constituting a "mute refusal" (p. 20). Withholding by non-response to a FOIA request is unique in that the administrative agency's own self-interest can be at stake (Kwoka, 2013, p. 187). Refusals can often have no basis in law, and often revolve around record management problems (LaMay et al., 2013 , p. 8). Lack of public awareness of the law itself has also led to fewer requests from journalists and private citizens around the world (LaMay et al., 2013, p. 6; Roberts, 2010, p. 929). Some specific implementation issues in India include lack of public awareness of the Act; lack of training among public officials; a backlog of appeals due to lack of resources; and a bias towards appointing retired government servants as commissioners, leading to the appearance of non-independence (Roberts, 2010, pp. 929931)

Information is still viewed as power in many developing countries (Tarpnell \& Lemieux, 2014, p. 11), and Roberts (2010) argues that commonwealth countries in particular have absorbed the British bureaucracy's "penchant for secretiveness" (p. 926). Trapnell \& Lemieux (2014) have found from their analysis of implementation of FOIAs around the world that political support is a major driver of effective and sustained implementation (p. 29). As a result, for the proper implementation of FOIAs in developing countries, it is necessary to overcome both capacity constraints and competing domestic resistance. The Caribbean region is no exception to these general global trends.
FOIAs in the Caribbean: implementation, capacity constraints and new developments

Legislation on FOIA in the Caribbean is a relatively recent phenomenon. The first FOIA in the region was passed in Belize in 1994. In 1999, the Commonwealth Law Ministers put forward Commonwealth Freedom of Information Principles, and endorsed the passage of FOIA legislation. That same year Trinidad \& Tobago passed legislation on FOIA. It took several years for the next FOIA to be passed in Jamaica in 2002. In 2008, the HIPCAR project was launched in the Caribbean, promising Harmonization of ICT Policies, Legislation and Regulatory Procedures in the Caribbean, providing an impetus for further FOIA Acts in the region. Similar to other developing countries, the passage of FOIAs in the region has been influenced by civil society, local and international press associations, and regional and international organizations (Durrant, 2006, p. 1). However, enactment and implementation of FOIAs in the Caribbean has generally been characterised by delay. Bills often languish for many years without being passed, and, even when passed, many Acts are not implemented for some time. For example, in Bermuda, the Public Access to Information Act took over five years to implement (Livingston, 2015, p. 11). In Grenada, the 2007 Freedom of Information Bill has yet to be enacted, and the 2009 Bill in St Lucia has yet to be made law. Table 1 characterises regional legislation in several stages, including implementation issues encountered by various countries in the region.

A number of common implementation issues can be identified, including lack of public awareness and insufficient training of public officials. Livingston (2015) identifies two main hurdles to implementation in the region: procedural and financial. Procedural obstacles 
primarily involve delays, including nonresponsiveness, or delays in responses to requests, as well as a delay in the appointment of information commissioners, and underreporting by their offices. Financial obstacles include a lack of resources, lack of training of public officials, and lack of digitization of records or maintenance of websites (p. 10). The region has particular capacity challenges in relation to data management. Taylor (2011)

Table 1

Stages of FOIA Legislation in Selected Caribbean Nations notes that, in the Caribbean, there is limited access to high-quality data, and limited availability of structured, current, machinereadable and locally relevant data (p. 23). She notes that more emphasis needs to be placed on data gathering, data systemization and data analysis $(2015$, p. 23). These data challenges could explain the delays in implementation, and the lack of responsiveness to requests in the region.

\begin{tabular}{|c|c|}
\hline Stage 1 & No FOIA - Bill only or Act not enacted \\
\hline St. Kitts and Nevis & Bill published in 2006 \\
\hline St. Lucia & 2009 Bill online but not passed \\
\hline Grenada & 2007 Bill online but not passed \\
\hline Stage 2 & FOIA legislation passed and implemented but with significant problems \\
\hline Antigua and Barbuda & $\begin{array}{l}\text { 2004 Act: } \\
\text { - Information Commission recently appointed, } \\
\text { - Lack of training and officials unaware of their legal obligations }\end{array}$ \\
\hline Belize & $\begin{array}{l}\text { 1994 Act (updated in 2000): } \\
\text { - } \quad \text { Legislation not fully implemented, access officers not appointed, } \\
\text { - } \quad \text { Powers of Information Commissioners limited, } \\
\text { - Few requests made and lack of public awareness }\end{array}$ \\
\hline The Bahamas & $\begin{array}{l}\text { 2017 Act: } \\
\text { - Not fully implemented - only appointment of Information Commissioner } \\
\text { and training provisions in effect, } \\
\text { - Lack of training and public awareness of Act, } \\
\text { - Public officials not aware of legal obligations }\end{array}$ \\
\hline Stage 3 & FOIA enforced but with some implementation issues \\
\hline Cayman Islands & $\begin{array}{l}\text { 2007 Act: } \\
\text { - Proactive Information Commissioner creates appearance of autonomy, } \\
\text { - Budget cuts have reduced size of the office, } \\
\text { - Need for more civil society assistance in publicizing the Act }\end{array}$ \\
\hline Jamaica & $\begin{array}{l}2002 \text { Act: } \\
\text { - Strong support from civil society coalitions including media and NGOs }\end{array}$ \\
\hline St Vincent \& Grenadines & $\begin{array}{l}2003 \text { Act: } \\
\text { - Limited appeal rights, } \\
\text { - Act in process of review }\end{array}$ \\
\hline Trinidad and Tobago & $\begin{array}{l}1999 \text { Act: } \\
\text { - Lack of public awareness leading to few requests, } \\
\text { - Unit staff cuts, } \\
\text { Judicial review process of appeal cumbersome. }\end{array}$ \\
\hline
\end{tabular}

Note. The table has been adapted and updated from the Caribbean Network on Freedom of Information. (2013). Action plan to improve FOIA implementation in the Caribbean. 
Recent developments in the Caribbean could point to a new and improved approach to FOIAs. For the first time, in 2013, Caribbean government officials and members of civil society met to discuss public participation in governance and access to justice. The meeting launched the Caribbean Network on Freedom of Information (or CNOFI), to support advocacy, the implementation of standards, and the spread of best practices (Livingstone, 2015 , p. 15). National initiatives such as the public reporting of discrepancies and corruption in environmental policies in Jamaica, as well as the Disclosure Today reporting mechanism in Trinidad \& Tobago on procurement irregularities, have also broadened the scope and reach of transparency initiatives in the region (Livingston, 2015, p. 15).

In 2012, ten Latin American and Caribbean countries signed the Declaration on the application of Principle 10 of the Rio Declaration on Environment and Development in Latin America and the Caribbean. Principle 10 of the Rio Declaration states that environmental issues are best handled with the participation of all concerned citizens; it promotes public participation, access to information and access to environmental justice. Signatories to the 2012 Declaration agreed to negotiate a regional instrument to improve access to information, encourage public participation, and strengthen access to justice in order to further implement sustainable development. As of April 2016, 21 countries from Latin America and the Caribbean are signatories to the Declaration, including six Caribbean countries. The seventh regional meeting took place in July and August 2017, and it is anticipated that a regional instrument will be adopted in the near future. Such an agreement should provide further impetus to the passage and fuller implementation of FOIAs in the region.

Despite these new developments, Caribbean countries will have to overcome significant capacity constraints to ensure the smooth operation of FOIA regimes. Part of the implementation process consists of surmounting domestic political resistance. The Bahamas exemplifies regional experiences of delay in the passage of FOIA Acts, and the following section charts the course of the passage, amendment and repassage of the 2017 Act in The Bahamas.

\section{FOIA in The Bahamas: delays, amendments, public consultation and political reticence}

On April 12, 2012, just before a general election, a Freedom of Information Act was passed by Parliament in The Bahamas. The Act was never enacted and the new Government decided to review the 2012 Act before bringing it into force. A working committee was appointed to undertake this review in 2014, and consisted primarily of attorneys from the Attorney General's office, the Director of Archives, a representative from the Ministry of Education and a representative of civil society from the University of The Bahamas. The working committee reviewed legislation from several jurisdictions including the United Kingdom, New Zealand and Canada, regional examples from the Cayman Islands, Jamaica, Trinidad \& Tobago, as well as the Model InterAmerican Law on Access to Public Information. A number of changes were made to the 2012 Act, including removing a Ministerial veto; narrowing the scope of exemptions, including guidance on the definition of the public interest in the accompanying Regulations; expanding the class of accessible documents to include policy documents; and boosting the independence of the Information Commissioner (Freedom of Information Act 
Working Committee, 2016).

On May 18, 2015 a revised Bill was made available to the public for comment. By the end of 2015, the working committee had only received two sets of comments on the Bill, and only one from a domestic organization, Citizens for a Better Bahamas. The working committee decided to engage in a period of public consultation on the 2015 Bill, holding two town hall meetings between April and June 2016 in the capital, Nassau, and three town hall meetings in family islands. Members of the public who attended had several common complaints. Many requested more information about the 2015 Bill, and expressed particular concerns about the appointment process of the Information Commissioner. While the 2015 Bill specifically stated that the Information Commissioner was to be independent and autonomous of Government, the appointment process remained the same as in the 2012 Act: the Information Commissioner was to be appointed by the Governor General on the advice of the Prime Minister in consultation with the Leader of the Opposition. One participant noted this appointment process would make the Information Commissioner "too political" and would feed into an existing culture and fear of victimization.

At another town hall meeting, members of the public expressed their view that the sunset clause of 30 years was too long and was out of line with regional examples. At two town hall meetings, the public voiced concern about what they viewed as a culture of secrecy pervading both the Cabinet and Government Departments. Some in attendance felt that FOIA should supercede the Official Secrets Act, but worried that the Bill, as written, would not. Several members of the public said that they supported discrete and full legislation to protect whistleblowers. Finally, in many town hall meetings the public requested that a specific, detailed definition of the "public interest" be included within the Act itself.

During this period, a new civil society organization called the Organization for Responsible Government, or ORG, was developed. Part of its mandate was to raise public awareness of the importance of FOIA, provide recommendations to the working committee, and hold its own public meeting, which included representatives of the working committee as well as other civil society organizations. As a result of these various public outreach initiatives, the legislation itself received heightened media attention, and the working committee received more written comments on the 2015 Bill.

In response to the comments received during the public consultation period, the working committee provided several recommendations for further amendments to the Bill, which were submitted for Cabinet approval in December 2016. These recommendations included adding a discrete public interest definition in the Act and reduced sunset clause period, as well as options for a more inclusive and independent appointment process for the Information Commissioner. Some of these recommendations were included in the revised December 2016 Bill that was debated in Parliament on January 31, 2017.

The Parliamentary debate was notable in two ways. First, all members of the opposition, while suggesting recommendations for amendments, declared support for the 2016 Bill. Further amendments to the Bill had been sent to Parliamentarians by those civil society organizations with specific recommendations to offer. Second, parliamentarians voiced a distinct hostility towards civil society participation. Two members of Parliament stated during the debate that "the country was being used" [by these NGOs] and that NGOs were trying to "destabilize" the Government. 
This hostility demonstrated competing domestic political narratives; while a public consultation period was undertaken by the working committee and endorsed by the Government, Parliamentarians themselves were distrustful of comments that were provided by NGOs, indicting a resistance to including these organizations in the implementation process.

The Act was passed and enacted on March 31, 2017, but only the provisions regarding the appointment of the Information Commissioner and training came into effect on April 21, 2017. After the general election on May 10, 2017, the Government changed again, and it is unclear at the time of writing whether more amendments will be made to the 2017 Act, or whether or when further provisions of the 2017 Act will be brought into force.

\section{Conclusion: some recommendations for the way forward}

The Bahamian experience in the passage, review, amendment, and re-passage of a FOIA illustrates the regional characteristics of delays in passage and implementation of this type of legislation. These delays can be attributed both to political reticence but also to the desire for further and deeper public awareness of the legislation on the part of the working committee. The Bahamas is now at the point of implementing the 2017 Act, and some important lessons can be learned from regional experiences. Engagement by civil society, including NGOs, is an important part of the process of the passage and implementation of FOIA. Therefore, any political hostility and distrust of these organizations should be overcome, and their resources used to help bridge the capacity gap in training and public awareness.

Experience from other developing countries has taught that, even if the legislation itself is not progressive, the appointment of an independent and active Information Commissioner is critical (LaMay et al., 2013, p. 8). The Cayman Islands has one of the best implementation regimes in the region, in large part due to the responsiveness of its Commissioner, which has garnered high public confidence in the regime (Livingston, 2015, p. 5). Jamaica, Trinidad \& Tobago and the Cayman Islands also followed a phased approach to implementation, allowing for training and the improvement of public records management before the Act came into effect (Livingston, 2015, p. 5). This phased approach can allow for government offices to develop their own internal implementation policies, fund and support compliance with the Act, and develop a unified and coherent classification system for FOIA requests (LaMay et al., 2013, p. 23). Building sufficient institutional capacity and oversight of the regime is also important. Implementation can also be helped along by providing appropriate enabling conditions in the public sector, which includes policy prioritization of transparency within government and support for a healthy and active civil society (Trapnell \& Lemieux, 2014, p. 25). IFLA has identified four foundational elements of successful implementation of access to information laws, which include appropriate infrastructure, positive social contexts, sufficient community capacity as well as favourable legal and policy landscapes (IFLA \& Technology \& Social Change Group, 2017, pp. 7-8). Finally, political support for not only a FOIA regime, but also for a broader policy network of transparency and accountability is critical to sustainable and effective implementation of a FOIA (Schnell, 2015, p. 286). While The Bahamas has followed regional examples of delay in the passage and implementation of the 2017 Act, important lessons can be learned from regional counterparts to ensure effective implementation of the Act. 


\section{References}

Caribbean Freedom of Information Network. (2013). Plan to improve FOIA implementation in the Caribbean. Retrieved from http://foiaadvocates.net/?page_id=10617

Durrant, F. (2006). Openness, access to government information and Caribbean governance. First Monday, 11(6), 1-4.

Retrieved from http://ojphi.org/ojs/index.php/fm/article/v iew/1369/1288

Freedom of Information Act Working Committee. (2016). Freedom of Information Bill 2015 town hall meeting. Retrieved from https://www.ministryofeducationbahamas .com/freedom-of-information

IFLA \& Technology \& Social Change Group, University of Washington. (2017). Development and access to information: Executive summary. Retrieved from https://da2i.ifla.org

Kwoka, M. B. (2013). Deferring to secrecy. Boston College Law Review, 54, 185242. Retrieved from http://bclawreview.org/files/2013/01/04_ kwoka.pdf

LaMay, C. L., Freeman, R. J., \& Winfield, R. N. (2013). Breathing life into freedom of information laws: The challenges of implementing in the democratizing world. Retrieved from http://www.cima.ned.org/wpcontent/uploads/2015/02/CIMAFreedom_of_Information_ISLP_09-1013.pdf

Livingstone, A. (2015). Freedom of information in the Caribbean 20 years \& beyond. Retrieved from

http://web.worldbank.org/WBSITE/EXT ERNAL/TOPICS/EXTPUBLICSECTOR ANDGOVERNANCE/0\%2c\%2ccontent MDK:23585462 pagePK:148956 piPK: 216618 theSitePK:286305\%2c00.html

Roberts, A. (2010). A great and revolutionary law? The first four years of India's Right to Information Act. Public Administration Review, 70(6), 925-933. https://doi.org/10.1111/j.15406210.2010.02224.x

Schnell, S. (2015). Mimicry, persuasion or learning? The case of two transparency and anti-corruption policies in Romania. Public Administration and Development, 35(4), 277-287. https://doi.org/10.1002/pad.1721

Shepherd, E. (2015). Freedom of Information: Right to access information, open data: Who is at the table? The Round Table, 104(6), 715-726. https://doi.org/10.1080/00358533.2015.1 112101

Taylor, K. C. (2011). A review of information, data protection and open data in the Caribbean. Retrieved from http://caribbeanopeninstitute.org/civicrm/ file? reset $=1 \& \mathrm{id}=1 \&$ eid $=7$

Trapnell, S. E., \& Lemieux, V. (2014). Right to information: Identifying drivers of effectiveness in implementation. Washington, DC: World Bank. Retrieved from http://documents.worldbank.org/curated/e n/157641467997846547/Right-toinformation-identifying-drivers-ofeffectiveness-in-implementation 